\title{
Prosthesis-patient mismatch: Don't forget this match!
}

\author{
Francesco Formica, MD, and Stefano D'Alessandro, MD, FECTS
}

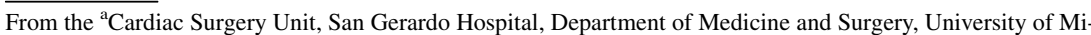 \\ lano-Bicocca, Monza, Italy. \\ Disclosures: Authors have nothing to disclose with regard to commercial support. \\ Received for publication April 12, 2018; accepted for publication April 12, 2018; available ahead of print May 17, \\ 2018. \\ Address for reprints: Francesco Formica, MD, Clinica Cardiochirurgica Ospedale San Gerardo, ASST Monza Via \\ G.B. Pergolesi 33, Monza (MB) 20052, Italy (E-mail: francesco_formica@ fastwebnet.it). \\ J Thorac Cardiovasc Surg 2018;156:1353-4 \\ $0022-5223 / \$ 36.00$ \\ Copyright (C) 2018 by The American Association for Thoracic Surgery \\ https://doi.org/10.1016/j.jtcvs.2018.04.056
}

In this issue of the Journal, Sabik III and colleagues ${ }^{1}$ report their experience with a novel bovine pericardial stented aortic bioprosthesis named Avalus (Medtronic, Minneapolis, Minn). A total of 864 selected low-risk patients underwent isolated aortic valve replacement or combined with other cardiac procedures in 36 sites worldwide. Among 864 patients who received the study valve, 577 completed the 1-year follow-up. In this trial, the authors reported a low early mortality $(1.2 \%)$ and a high 1-year survival $(96.4 \%)$. Furthermore, the late linearized rates for thromboembolism $(1.7 \%)$, prosthetic valve leakage $(0.6 \%)$, endocarditis $(1.3 \%)$, and explant $(0.7 \%)$ were comparable with other studies. Functional class improved dramatically and at 1-year follow-up, $73.7 \%$ of 577 patients were in New York Heart Association functional class I. Last but not least, mean aortic peak gradient was reduced strongly and at 1-year follow-up was $12.5 \pm 4.4 \mathrm{~mm} \mathrm{Hg}$. By these early and late clinical and hemodynamic excellent results, the authors can demonstrate that the new Avalus bioprosthesis is associated with low overall mortality, low valve-related adverse events, and excellent hemodynamic performances comparable with all other stented bovine bioprosthesis. $^{2-7}$

Nevertheless, some topics of this study must be addressed. One non-negligible aspect concerns the incidence of prosthesis-patient mismatch (PPM); the authors reported a surprising incidence of moderate $(43.6 \%)$ and severe $(22 \%)$ PPM at 30 days with a slight increase at 1-year follow-up ( $46 \%$ and $29.5 \%$, respectively). It is known that at the time of surgery the surgeon needs to reduce the risk of PPM, which is associated with worsening hemodynamics, decreased regression of the left ventricular mass, increased incidence of cardiac events, reduced survival, and early degeneration of the bioprosthesis.

The authors failed to give an explanation of their high rate of PPM, which does not correspond to the improvement of the clinical status nor to the favorable reduction of the mean transprosthetic gradient. It would have been, for instance, very interesting to know the trend of the variation

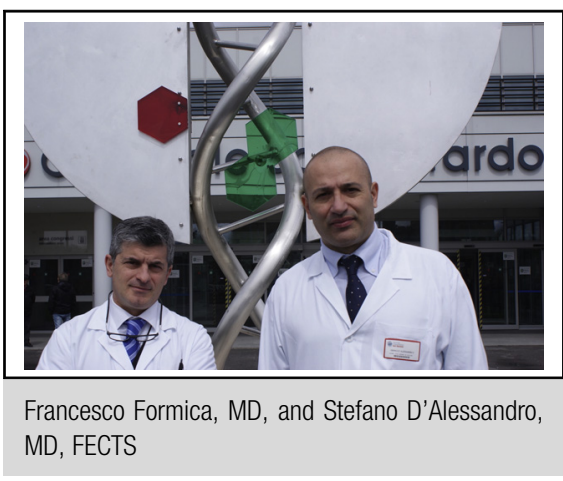

Central Message

The Avalus bovine bioprosthetic valve is associated with promising 1-year follow-up. Longer follow-up will be needed to determine the durability of the prosthesis and the rate of prosthesis-patient mismatch.

See Article page 1368.

of the left ventricular mass during the follow-up, aiming at studying any correlation with PPM. Many factors may cause PPM, such as an unsuitable sizing of the prosthesis, the geometry of the bioprosthesis, and a very small aortic annulus that may affect the sizing. Therefore, for those reasons we understand that it is difficult to provide an explanation about this issue. Another topic concerns the incidence $(2.5 \%)$ of major bleeding per valve-year, most of which occurred in patients who were on antithrombotic therapy before surgery. Major bleedings are reported with varying incidence in different studies, and often the cause is multifactorial and does not depend on by the bioprosthesis per se.

That said, the eminent authors of this study have to be congratulated for their results, which demonstrate the new Avalus valve to be competitive with other bovine bioprostheses already well known and used worldwide. However, we have to keep in mind that PPM could become a challenging match to face. We are looking forward to reading a new study of theirs on this issue.

\section{References}

1. Sabik JF III, Rao V, Lange R, Kappetein AP, Dagenais F, Labrousse L, et al. One year outcomes associated with a novel bovine pericardial stented aortic bioprosthesis. J Thorac Cardiovasc Surg. 2018;156:1368-77.

2. Lorusso R, Gelsomino S, Lucà F, De Cicco G, Billè G, Carella R, et al. Type 2 diabetes mellitus is associated with faster degeneration of bioprosthetic valve: results from a propensity score-matched Italian multicenter study. Circulation. 2012;125: 604-14.

3. ISTHMUS Investigators. The Italian study on the Mitroflow postoperative results (ISTHMUS): a 20-year, multicentre evaluation of Mitroflow pericardial bioprosthesis. Eur J Cardiothorac Surg. 2011;39:18-26. 
4. Bavaria JE, Desai ND, Cheung A, Petracek MR, Groh MA, Borger MA, et al. The St Jude Medical Trifecta aortic pericardial valve: results from a global, multicenter, prospective clinical study. J Thorac Cardiovasc Surg. 2014; 147:590-7.

5. Goldman S, Cheung A, Bavaria JE, Petracek MR, Groh MA, Schaff HV. Midterm, multicenter clinical and hemodynamic results for the trifecta aortic pericardial valve. J Thorac Cardiovasc Surg. 2017;153:561-9.e2.
6. Conte J, Weissman N, Dearani JA, Bavaria J, Heimansohn D, Dembitsky W, et al A North American, prospective, multicenter assessment of the Mitroflow aortic pericardial prosthesis. Ann Thorac Surg. 2010;90:144-52. e1-3.

7. Johnston DR, Soltesz EG, Vakil N, Rajeswaran J, Roselli EE, Sabik JF III, et al Long-term durability of bioprosthetic aortic valves: implications from 12,569 implants. Ann Thorac Surg. 2015;99:1239-47. 